\title{
VENTRICULAR EXTENSION INTO THE ABDOMINAL WALL
}

BY

\author{
CLIFFORD PARSONS \\ From the Birmingham Children's Hospital
}

Received April 3, 1956

In a previous paper mention was made of a girl with cyanotic congenital heart disease and a pulsatile tumour under the umbilicus (Astley and Parsons, 1953). This child died in Birmingham Children's Hospital in 1950, but the condition was thought to be a chance monstrosity until 1952, when Dr. Helen Taussig referred in a letter to another example of this condition. In 1955 both Dr. Catherine Neill and Dr. James Brown drew my attention to descriptions of other similar cases.

\section{CASE REPORT}

M. A., the fifth child of a healthy family, was born after a pregnancy complicated by a small hæmorrhage at the third month. A pulsating swelling at the umbilicus was noticed at birth; intermittent cyanosis was first observed six months later. Cyanotic attacks became increasingly severe and frequent, especially when feeding or crying, and she was unconscious when, at the age of 18 months, she was admitted to hospital for the last time in one of these attacks. She was quite well-developed, and uniformly cyanosed, with moderate clubbing of fingers and toes (hæmoglobin, $14.7 \mathrm{~g}$.; red blood corpuscles, 6.8 million). The venous pressure was raised, the liver enlarged, and the lungs slightly congested. Arterial pulses were normal, and the blood pressure in the arms $120 / ? 100 \mathrm{~mm}$. Apical impulses could be felt in the fourth left intercostal space just internal to the mid-clavicular line, and in the fifth right space in the mid-clavicular line; the chest was not deformed. A systolic thrill was felt at the right sternal margin in the second and third spaces and a harsh systolic murmur was heard all over the front of the chest, and faintly between the scapulæ. A systolic thrill and a continuous murmur could be detected over a smoothly-rounded, pulsatile swelling immediately deep to the umbilicus. A straight cord, which also pulsated, ran under the skin between the epigastric notch and the upper border of the tumour. The depth of cyanosis was not affected by compressing the tumour or its connections. X-ray examination supported a diagnosis of dextrocardia, but an electrocardiogram, using only the standard limb leads, showed peaked P waves in lead II, marked left axis deviation, and rather wide ventricular complexes, suggesting the possibility of tricuspid atresia with a diminutive right ventricle. No further investigations were possible until after death, when radioopaque material injected into the superior vena cava demonstrated a communication between right and left atria, and outlined the pulmonary veins. An injection into the sub-umbilical tumour showed connections with the aorta and its branches through a ventricle.

Necropsy. The only abnormalities were those related to the heart. Externally (Fig. 1) the aorta and pulmonary artery appeared to arise from two ventricles separated by an interventricular groove; the right atrium was dilated. The apex of the heart was fusiform and continued downward as a muscular tube " like an anteater's snout" to an ovoid tumour $(27 \times 18 \times 10 \mathrm{~mm}$.) lying deep to the umbilicus. Unfortunately the reflections of the pericardium were not adequately examined, but a membrane attached to the front of the tube in its upper part was presumably the anterior mesocardium.

Dissection confirmed that the right atrium was large, receiving both venæ cavæ and the pulmonary veins from the right lung. It did not communicate with the right ventricle but opened into the left atrium through a high septal defect. No ridge in the roof marked the position of the septum secundum and the division between the atria; the lower part of the interatrial septum was intact. The left atrium was somewhat smaller than the right, receiving the left pulmonary veins and emptying through a normal bicuspid mitral valve into an enormously hypertrophied left ventricle, with a wall $17 \mathrm{~mm}$. thick. The aorta was $32 \mathrm{~mm}$. in circumference at its ostium, and the aortic valve, coronary arteries, aortic arch and its branches 
were all normal and the ductus arteriosus was closed. The right ventricle was represented by a thin-walled narrow tube, $7 \mathrm{~mm}$. in circumference and with a smooth internal surface, lying on the surface of the left ventricle adjacent to the interventricular groove (Fig. 2). This tube opened through a bicuspid pulmonary

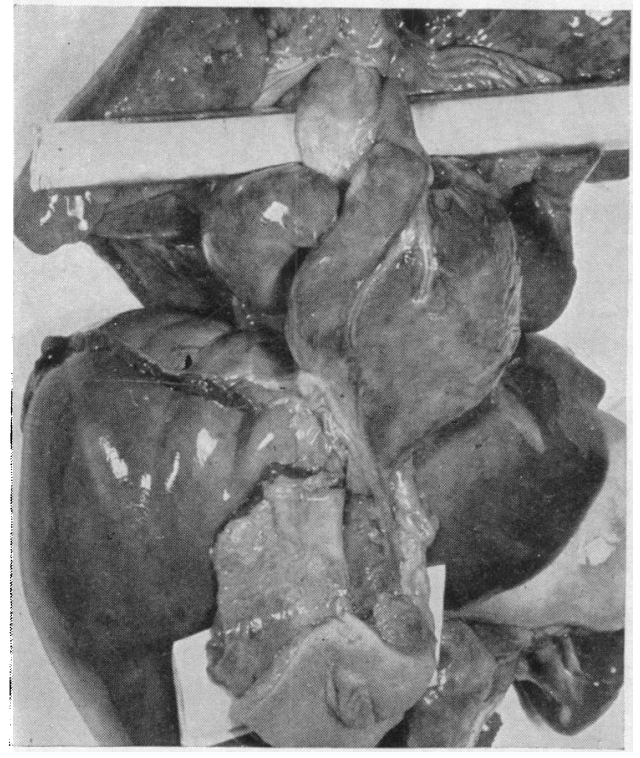

FIG. 1.-Complete specimen. The skin of the umbilicus can be seen at the bottom of the illustration and the ventricular extension is a little to the right of the mid line.

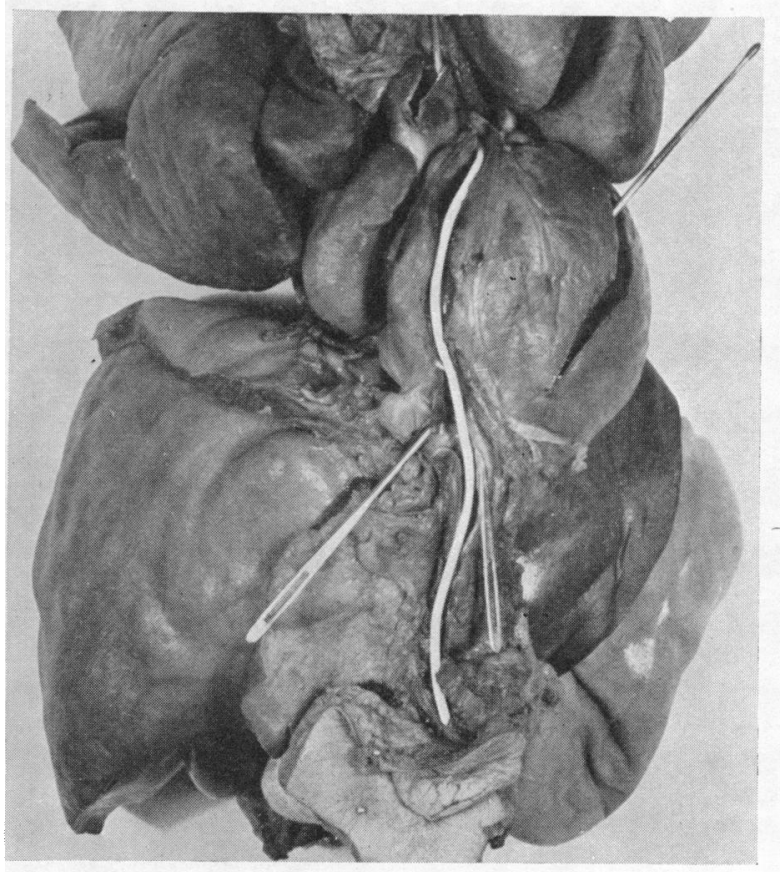

FIG. 2.-Specimen opened. The white marker runs through the ventricular extension and right ventricle into the pulmonary artery; the vertical probe runs from the ventricular extension through the left ventricle into the aorta; the oblique probe runs through the interventricular septal defect.

valve into a pulmonary artery which was normally distributed but hypoplastic (circumference $16 \mathrm{~mm}$.). A channel $3 \mathrm{~mm}$. in diameter led from left to right ventricle through the muscular septum. A rudimentary valve, with two chordæ tendineæ but no cusps, guarded its opening into the right ventricle. Another narrow channel connected the extreme apex of the left ventricle with the lower end of the right ventricle (Fig. 3). An extension of the right ventricle formed a muscular tube leading to what looked like a third ventricle, a muscular chamber with a trabeculated inner surface (Fig. 4). In this structure also myocardial fibres were hypertrophied, and there was interstitial fibrosis. The endocardium was thickened and fibrotic.

\section{Discussion}

Formijne (1950) observed a somewhat similar condition in a 30 -year-old woman who died during thoracotomy. She was found to have two superior venæ cavæ, tricuspid atresia, a wide atrial septal defect, a small ventricular septal defect and a rudimentary right ventricle. The " trunk-like" prolongation towards the umbilicus was an extension of the left ventricle. This was true, also, of a male infant described by Snellen et al. (1952). In this case there was a persistent anterior mesocardium and a high ventricular septal defect. All four chambers were enlarged; the right ventricle being larger than the left, and the pulmonary artery larger than the aorta. This patient had been fully investigated during life, angiocardiograms were taken and catheterization performed. The physical signs and X-ray findings were much the same as in those described in the present case, but an electrocardiogram showed right ventricular preponderance. 


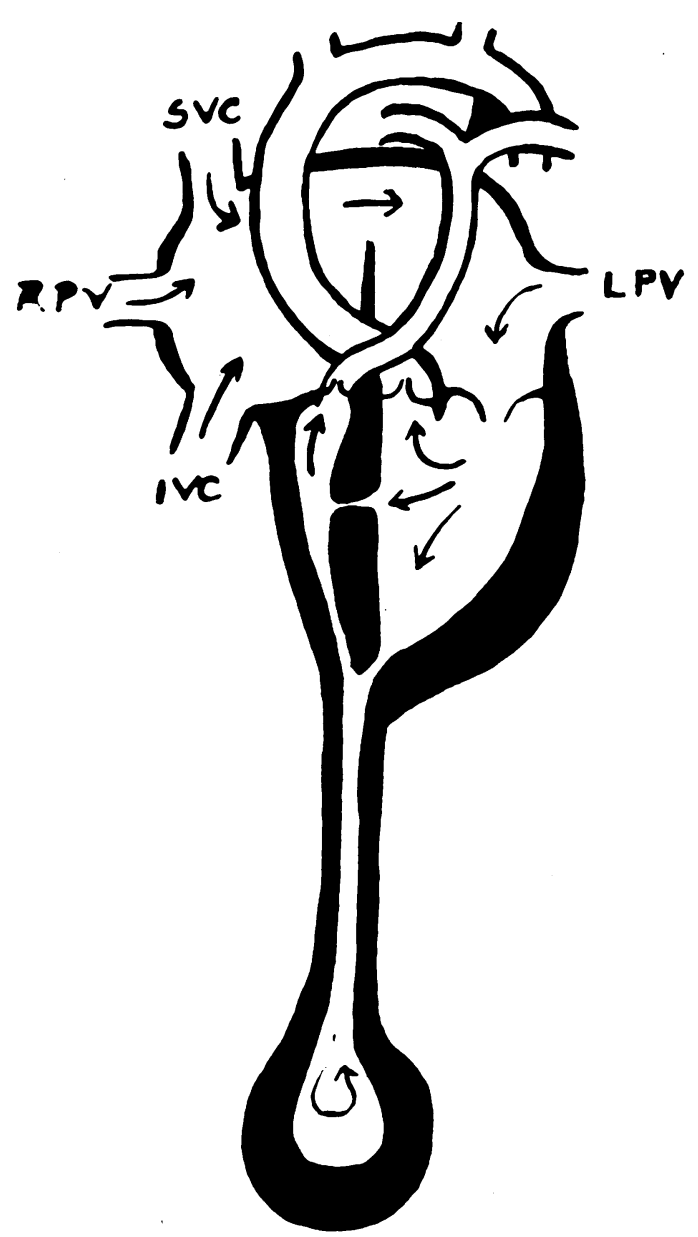

FIG. 3.-Diagrammatic representation of the anomaly.

There is a sufficient similarity between these three cases to suggest a common defect in development. The heart develops in the neck and migrates to the thorax in close association with the septum transversum, which forms a diaphragm separating the heart from the abdominal cavity and the yolk sac. The separation becomes still more marked when, in the seventh week, the rapidly growing liver bulges forward and interposes an even thicker layer between the heart and the stalk of the yolk sac, which by now is being incorporated into the umbilical cord. If, therefore, the elongated diverticulum characteristic of these three cases is due to the developing heart being caught up in the umbilical structures, the defect must occur very early in embryonic life.

In the fourth week the cardiac tube is elongating rapidly and, as it is fixed at both ends, it forms a loop. It lies in the splanchnic mesoderm - into which the liver is just beginning to grow-and, because the embryo is acutely flexed, the apex of this ventricular loop presses against the yolk sac. If the heart wall were to become attached to the structures of the yolk sac at this stage, the ventricular loop would be drawn out in front of the rapidly growing liver as the embryo straightened. The diverticulum so formed might be made up of tissue needed for the normal development of either ventricle, and in consequence that chamber would be deformed. In turn this might influence the development of the atrio-ventricular canal-contributing in our patient to the tricuspid valve deformity, and so to the maintenance of an interatrial communication. 


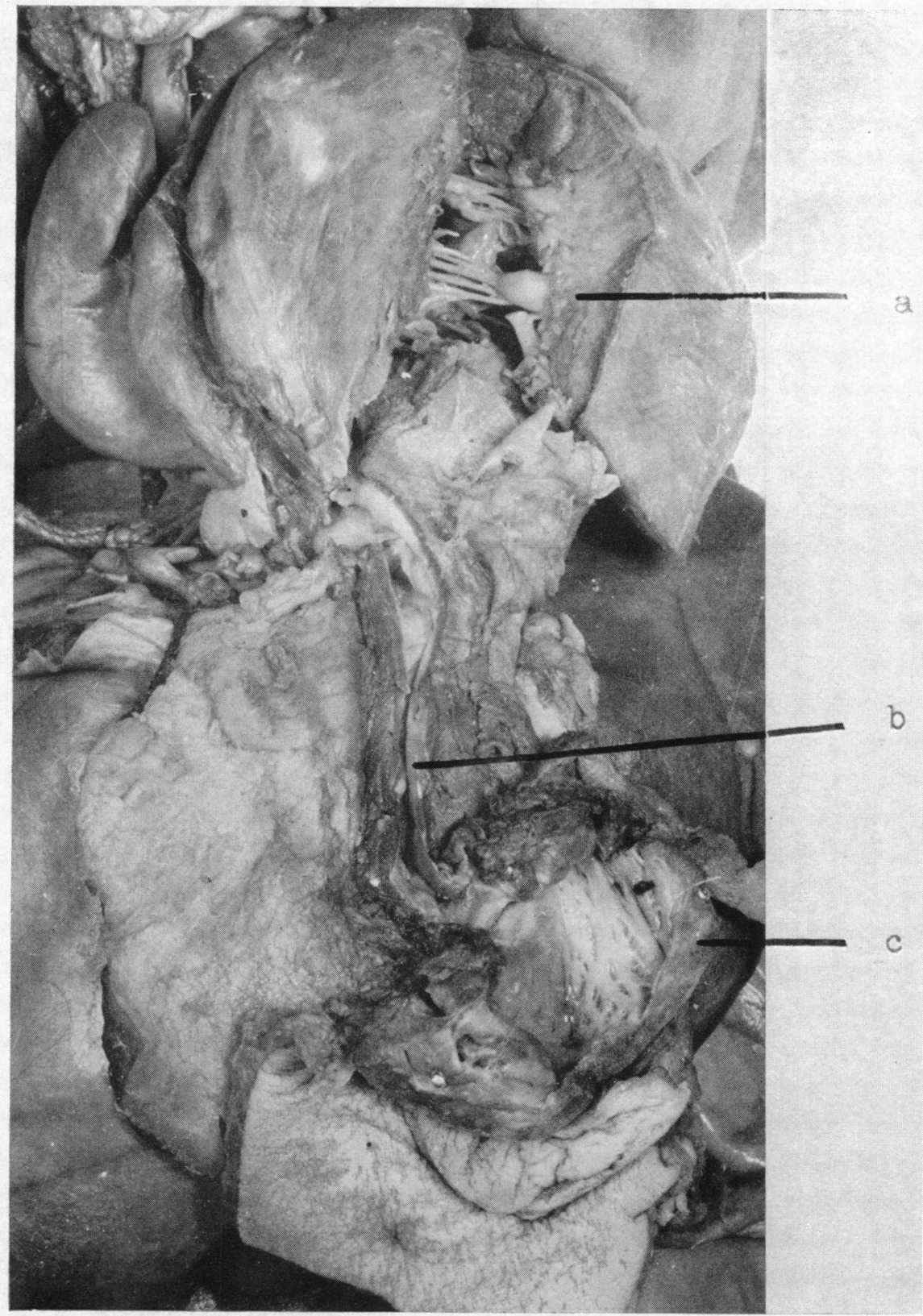

There is another reason for assuming that arrest of development occurred at about the fourth week. Early in the life of the embryo the endothelial tubes that form the heart and the gut are enfolded by the splanchnic mesoderm, giving to the heart, the gut, and later the liver, a dorsal and a ventral mesentery. The hepatic ventral mesentery persists as the falciform ligament. The intestinal ventral mesentery quickly disappears (except where it is attached to the foregut on the cranial side of the yolk sac) and in embryos $2 \mathrm{~mm}$. long both dorsal and ventral mesocardia have 
also disappeared and the heart already lies free in the pericardium. It follows that persistence of a ventral mesocardium is indicative of a defect occurring before the end of the fourth week. Snellen et al. (1952) carefully studied the pericardial reflections in their case and demonstrated prolongations of the pericardial cavity, one lying behind and one on either side of the muscular tube. The anterior surface of the myocardial tube was not covered by pericardium, but a ventral mesocardium was clearly recognized. It was probably present in our case also.

\section{SUMMARY}

A rare developmental anomaly of the heart is described. It consisted of tricuspid atresia, atrial septal defect, abnormal drainage of the right pulmonary veins, hypertrophied left ventricle, diminutive right ventricle, hypoplastic pulmonary artery, and a tubular extension of the right ventricle lying in the anterior abdominal wall. Reasons are given for thinking that it arose during the fourth week of fœtal life.

\section{REFERENCES}

Astley, R., and Parsons, C. G. (1953). Brit. Heart J., 15, 289.

Formijne, P. (1950). Nederl. Tijdschr. v. Geneesk., 94, 2704.

Snellen, H. A., Dankmeijer, J., Bruin, C., and Collister, R. M. (1952). Cardiologia, 21, 563. 